\title{
Guidelines for a wheelchair ergonomic adaptation based on dynamometry and surface electromyography
}

\author{
Lincoln da Silva ${ }^{a}$ Eugenio Andrés Díaz Merino ${ }^{a}$ Julia Marina Cunha ${ }^{b}$ Giselle Schmidt Alves Díaz Merino", \\ Fausto Orsi Medolac, Luis Carlos Paschoarellic \\ aDepartamento de Engenharia de Produção, Universidade Federal de Santa Catarina - UFSC \\ 'Departamento de Design, Universidade Federal de Santa Catarina - UFSC \\ 'Departamento de Design, Universidade Estadual Paulista - UNESP \\ e-mails: lincolnsilvafsio@gmail.com; eugenio.merino@ufsc.br; juliamarina@gmail.com; gisellemerino@gmail.com; fausto.medola@faac.unesp.br; \\ paschoarelli@facc.unesp.br
}

\begin{abstract}
The aim of this study was to define design guidelines for an ergonomic adaptation in wheelchairs based on the upper limbs myoelectric activity evaluation of an experient manual wheelchair user, in flat and inclined grounds (ramp). The wheelchair use activity was carried out in a pre-established route that involved flat and inclined grounds (ascending). The data collection procedures were: socio-demographic questionnaire, hand grip dynamometry and surface electromyography. Therefore, the results found indicate, specifically, greater activity in the Flexor Digitorum Superficialis muscle groups bilaterally, which are the muscle groups responsible for assisting the manual grip on the wheel rim. In addition to this, there was a decrease in Medium Frequency values associated with an increase in the muscle use percentage, which may represent fatigue and inadequate physiological recovery of the muscle groups studied and may lead to severe musculoskeletal disorders. From the analysis of the physiological and biomechanical data, it was possible to identify biomechanical factors that may represent risks to the health of the wheelchair user, thus, design guidelines were suggested for an ergonomic adaptation that can reduce physical effort, mainly on inclined ground, aiming, specifically, to reduce the Flexor Digitorum Superficialis fatigue and increase the propulsion efficiency.
\end{abstract}

Keywords: wheelchair, assistive technology, EMG, ergonomics, hand grip.

\section{Introduction}

By promoting mobility, wheelchairs are a key part for the independence of People with Disabilities (PwD). In Brazil, about $7 \%$ of the population has some type of motor disability (INSTITUTO..., 2009), and approximately $1.85 \%$ of the world population requires the use of wheelchairs (WHEELCHAIR..., 2018). Although promoting mobility, manual wheelchairs may require excessive effort of the upper limbs (MULROY et al., 2004; BAYLEY; COCHRAN; SLEDGE, 1987), which may be related to the high prevalence of pain and discomfort in the upper limbs. Gellman, Sie and Waters (1988) found that $68 \%$ of wheelchair users report complaints of pain or discomfort. In a study with twentyeight paraplegic and quadriplegic subjects, wheelchair users, Medola et al. (2011) found a prevalence of $78 \%$ of pain among users, the region of the thoracolumbar spine and shoulders being the areas with the highest incidence.

Several factors influence the efficiency and satisfaction during wheelchair use, including those related to the product, the user and the context of use, such as flexibility of use, possibility of adaptation, anthropometric suitability, among others. When considering all these factors during product design, we seek to provide accessibility and inclusion. Accessibility is understood as the availability of good health services within reasonable reach of those who need them and of opening hours, appointment systems and other aspects of service organization and delivery that allow people to obtain the services when they need them (EVANS; HSU; BOERMA, 2013). In this context, the used routes conditions to access a place are important, as they may (or not) allow the accessibility of people with motor disabilities. Wheelchair users develop their activities on at least two types of terrain: flat and inclined; and in terms of biomechanical demand, these different terrains can change the relationship between product and user.

In this sense, the ergonomics applied to assistive technologies aims to identify the factors of the product that could enhance the user's capabilities. Thus, the wheelchair is considered a product with unique characteristics of use, 
since it is not only a device for mobility, but also a postural support interface, since users stay seated for about 11 hours a day, moving with it for $10 \%$ of the time (SONENBLUM; SPRIGLE; LOPEZ, 2012).

In order to perform the study of user interaction and the elements that make up the wheelchair, there is a need for methods that evaluate in real time and relate to the physiological and biomechanical characteristics inherent to the use of assistive technologies. Surface electromyography (EMG), because it is able to measure muscle activity in real time, and to relate to the physiological characteristics of muscle fibers, can be considered as a useful tool in ergonomic evaluations (MARRAS, 1990).

Thus, the aim of this study is to define design guidelines for an ergonomic adaptation in wheelchairs based on the upper limbs myoelectric activity evaluation of a manual wheelchair user when moving in flat and inclined ground (ramp), by means of surface electromyography.

\section{Material and methods}

This research can be characterized as applied regarding its nature, it has qualitative and quantitative, exploratory and descriptive approach. It is a case report with a male wheelchair user. The wheelchair use activity was carried out in a pre-established route that involved flat and inclined grounds (ascending) of a public access.

The Informed Consent Form and Consent Terms for Use of Image and Voice were submitted to the wheelchair user, with the presentation of the objectives and the relevance of the participation in the research, as instructed in the Resolution of the National Health Council (CNS) nr. 466, of December 12, 2012, which establishes Regulatory Guidelines and Norms Involving Human Beings.

The study was developed in three stages (Figure 1).

The data collection procedures were: socio-demographic questionnaire, hand grip dynamometry and surface electromyography.

\subsection{Sociodemographic questionnaire}

The sociodemographic questionnaire was used to define the wheelchair user social characteristics. For this purpose, the questionnaire was composed of information about age, gender, time of wheelchair use, work and physical activities.

\subsection{Isometric Hand Grip Dynamometry (IHGD)}

The IHGD was used to verify the health status of the musculoskeletal group responsible for the hand grip strength of the evaluated user, considering that this could influence the final result of the study, according to the high possibility of musculoskeletal disorders in upper limbs of wheelchair users. In addition, it served as a basis for the MIVC (Maximum Isometric Voluntary Contraction) data collection, in the electromyographic analysis.

The SAEHAN ${ }^{\circledR}$ brand hand grip dynamometer (SAEHAN Corporation, Korea, Model DIGI II) was used with a maximum capacity of $90 \mathrm{~kg}$ and a scale of $1 \mathrm{~g}$. At the time of the tests, the individual was positioned as recommended by the American Society of Hand Therapists

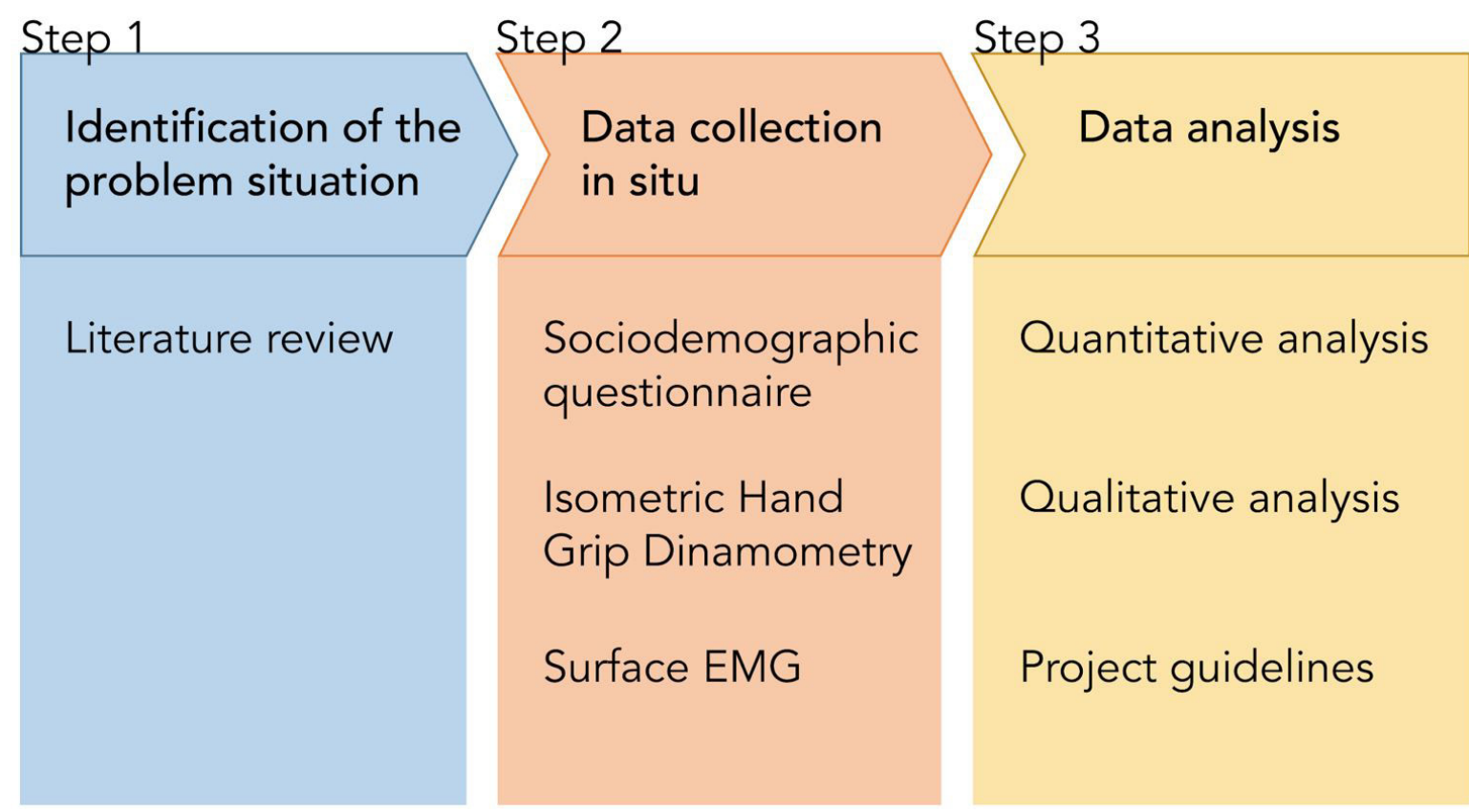

Figure 1. Research steps description. Source: The authors (2018). 
(ASHT) (FESS, 1992). Verbal command was given: "force, force ..." during the test and instructions for its execution were standardized. During the instructions, the volume of the verbal command remained constant to avoid any influence of the same on the magnitude of muscle contraction (TAYLOR; SHECHTMAN, 2000).

\subsection{Surface Electromyographic (EMG)}

It was used in order to verify muscle fatigue and the percentage of muscle fiber use during the displacement with the wheelchair. In order to verify the fatigue, the linear tendency of the MF (Median Frequency) was explored. It was also verified the percentage value of muscle usage, relating RMS (Root Mean Squares) and Maximal Voluntary Isometric Voluntary Contraction (MIVC).

The acquisition of electromyographic signals (EMG) was performed with a 4-channel Miotool 400 electromyograph $\left(\right.$ Miotec $\left.^{\circledR}\right)$. The system works with Miograph 2.0 USB software, where data is transmitted to a portable computer. The EMG signals were collected with a sampling rate of $2000 \mathrm{~Hz}$ for each channel, high pass filter of $5 \mathrm{~Hz}$, low pass filter of $500 \mathrm{~Hz}$ and $60 \mathrm{~Hz}$ notch filter.

For the recording of the electromyographic signal, pairs of surface electrodes of $\mathrm{Ag} / \mathrm{AgCl}$, pregelatinised $\left(\right.$ Meditrace ${ }^{\circledR}$ ), were used in bipolar configuration, with a capture area of $1 \mathrm{~cm}$ in diameter and $2 \mathrm{~cm}$ inter-electrode distance, with fixing adhesive. The electrodes were positioned bilaterally in the Triceps Brachii (lateral portion) (TBL) and Flexor Digitorum Superficialis (FDS) muscles, since these muscles act directly on forward wheel drive and hand gripping during hand coupling to the propulsion rim, respectively. The reference electrode was fixed in the right olecranon. All norms pertaining to the adequate recording of EMG signals recommended by the International Society of Electrophysiology and Kinesiology (ISEK) (MERLETTI; DI TORINO, 1999) were strictly observed.

Before electrodes were placed, the following procedures were performed: (1) identification of electrode fixation points, (2) tricotomy and abrasion of the skin, (3) 70\% alcohol hygiene, (4) electrodes placement (MORAES et al., 2003; O’SULLIVAN; SCHMITZ; FULK, 2017).
In order to normalize the EMG and obtain the CIMV in the manual isometric hand grip strength, with the electrodes positioned on the Right and Left Flexor Digitorum Superficialis (RFDS / LFDS), three tests were performed with 10 second resistance maintenance and with intervals of 1 minute between acquisitions. To define the MIVC of these muscles, the maximum value of manual isometric hand grip strength recorded in dynamometry was used. In order to verify the MIVC of the Right and Left Lateral Brachial Triceps muscle (RTBL / LTBL), isometric resistance was obtained contrary to elbow extension at 90 degrees of flexion with the the shoulder at 90 degrees of flexion, three tests with maintenance of 10 seconds of resistance and at intervals of 1 minute between the acquisitions were also performed.

Then, the electromyographic evaluation was performed in a real situation, in which the wheelchair user moved on a flat and inclined ceramic floor (Figure 2). The time of displacement and acquisition of the electromyographic signal was pre-determined by the authors, serving as the basis for the software miograph ${ }^{\circledR} 2.0$ configuration, with 20 seconds of displacement in flat floor, followed by 120 seconds of rest with the upper limbs placed on the legs, and finally 20 seconds of inclined ascendent displacement.

\subsection{Statistical analysis}

The results were tabulated in Microsoft Excel ${ }^{\circledR}$. Following this, they received statistical treatment with the help of IBM SPSS ${ }^{\circledR}$ software version 20.0. A comparative analysis was performed through the t-test of students for independent samples, two-tailed $(p<0.05)$. In the electromyographic application, a linear regression of the median (MF) values of the triceps brachii (lateral portion) (TBL) and the Flexor Digitorum Superficialis (FDS) were performed, aiming to observe the tendency of muscle fibers myoelectric fatigue.

\subsection{Design guidelines}

To define the design guidelines, some biomechanical risk factors were identified from the electromyographic analysis. Based on these factors, guidelines were suggested for an ergonomic adaptation of the manual wheelchair.

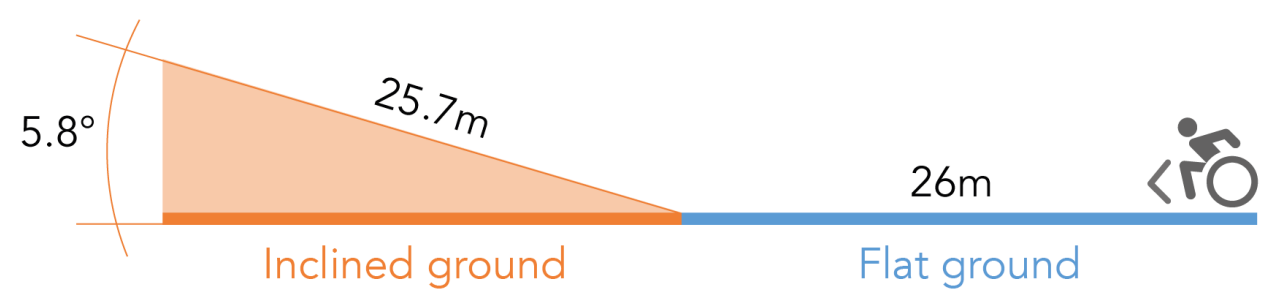

Figure 2. Traveled course. Source: The authors (2018). 


\section{Results}

\subsection{Sociodemographic questionnaire}

According to the sociodemographic questionnaire, the individual is a 43 years old male, right-handed, had a body mass of $75 \mathrm{~kg}$ and height of $1.69 \mathrm{~m}$. He is a regular swimming and basketball practitioner. He has been a wheelchair user for approximately 33 years, due to the polio sequel, diagnosed when he was 6 months old.

The wheelchair used is manually propelled Ortobrás ${ }^{\circledR}$ brand, Star Life model, weight of $12 \mathrm{~kg}$.

\subsection{Isometric Hand Grip Dinamometry}

The results of the Isometric Hand Grip Dynamometry are presented in Figure 3. It can be observed that the mean strength obtained for the dominant hand (right hand) was $41.43 \pm 2.1 \mathrm{kgf}$, and for the non-dominant hand (left hand) $46.56 \pm 0.7 \mathrm{kgf}$. It is noted that in all repetitions, the dominant hand exerted less strength than the non-dominant hand.

\subsection{Surface Electromyography (EMG)}

The electromyography was used in order to determine the physiological wear and the muscle use percentage related to the MIVC. The evaluated user obtained the values of MVIC $(\mu \mathrm{V})$ (RTBL: 981.5, LTBL: 997.2, RFDS: 402.9, LFDS: 404.9).

Table 1 presents the mean values and standard deviation of RMS $(\mu \mathrm{V}), \mathrm{MF}(\mathrm{Hz})$ and Percentual, normalized by the MIVC, of each evaluated muscle

Regarding the myoelectric activity observed through the RMS, MF and muscle use percentage in relation to the maximum contraction, a statistically significant difference was observed between the myoelectric activity in flat and inclined ground, characterizing higher values in inclined ground. The greatest difference in the use of the musculature in both grounds, obtained by subtracting the percentage

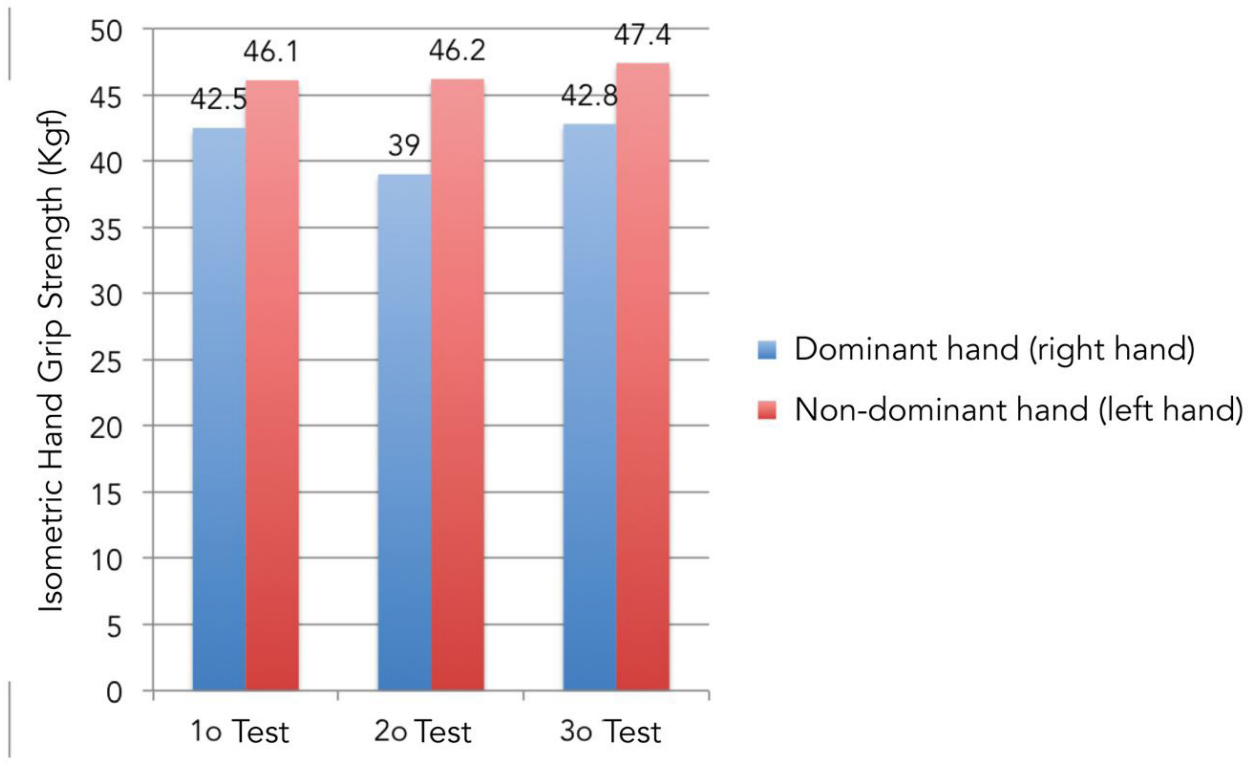

Figure 3. Isometric Hand Grip Strenght. Source: The authors (2018).

Table 1. Electromyography quantitative data.

\begin{tabular}{|c|c|c|c|c|}
\hline Ground & Muscle & RMS $(\boldsymbol{\mu V})$ & MF (Hz) & Percentage (\%) \\
\hline \multirow{3}{*}{ Flat } & RTBL & $109.17 \pm 26.4$ & $112.38 \pm 10.2$ & $10.66 \pm 2.7$ \\
\hline \multirow{4}{*}{ Inclined } & LTBL & $109.86 \pm 23.7$ & $124.47 \pm 14.1$ & $10.63 \pm 2.5$ \\
\cline { 2 - 5 } & RFDS & $62.23 \pm 17.6$ & $118.81 \pm 11.2$ & $14.43 \pm 4.2$ \\
\cline { 2 - 5 } & LFDS & $96.95 \pm 12.7$ & $125.41 \pm 11.3$ & $22.95 \pm 3.2$ \\
\hline & RTBL & $185.62 \pm 31.8$ & $111.86 \pm 5.1$ & $18.6 \pm 3.6$ \\
\cline { 2 - 5 } & LTBL & $211.065 \pm 72.3$ & $116.35 \pm 12.3$ & $22.49 \pm 7.5$ \\
\cline { 2 - 6 } & RFDS & $196.37 \pm 46.8$ & $116.18 \pm 10.6$ & $48.06 \pm 10.5$ \\
\hline & LFDS & $258.04 \pm 24.5$ & $118.68 \pm 3.6$ & $60.77 \pm 4.7$ \\
\hline
\end{tabular}

Source: The authors (2018). 
values and the $\mathrm{t}$ test, was found in $\operatorname{LFDS}(37.8 \%, \mathrm{p}=0.000)$, followed by RFDS (33.6\%, p = 0.174), LTBL (11.9\% ; $\mathrm{p}=0.002)$ and $\operatorname{RTBL}(7.9 \%, \mathrm{p}=0.000)$. It can be noticed that Flexor Digitorum Superficialis presented greater myoelectric activity in both lands. It is also observed that the dominant side presented lower values in relation to the non-dominant, denoting imbalances in their use.

Figure 4 presents the mean values of muscle use percentages for periods of $2 \mathrm{~s}$. It can be noticed a significant increase in the use of the FSD muscles in inclined ground, what configures a overload to the hand grip, and an imbalance in the use of the muscles responsible for the wheelchair propulsion in situations of greater physical exigency.
A decrease trend of the MF values on both grounds was also observed (Figure 5 and 6). On the flat ground, the decrease in MF values occurred in the muscles: RTBL, LTBL and LFDS, with LFDS having the higher value (Figure 5). On inclined ground, the decrease trend in MF values was manifested in the FSDs bilaterally, with the left side overcoming the right (Figure 6).

\subsection{Design guidelines}

Considering the quantitative and qualitative analysis of the collected data, the identified risk factors are presented, and the design guidelines were defined for an ergonomic adaptation of the manual propulsion wheelchair, presented in Table 2.

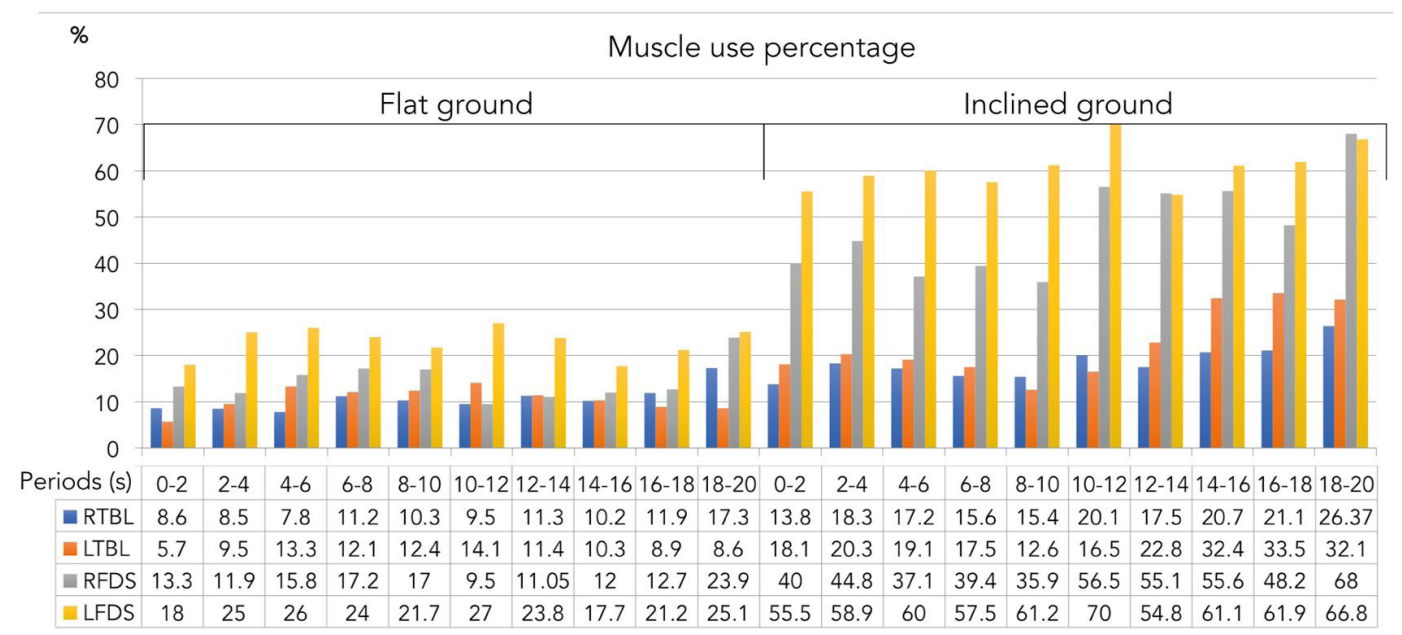

Figure 4. Musculature use percentage during wheelchair propulsion. Source: The authors (2018).

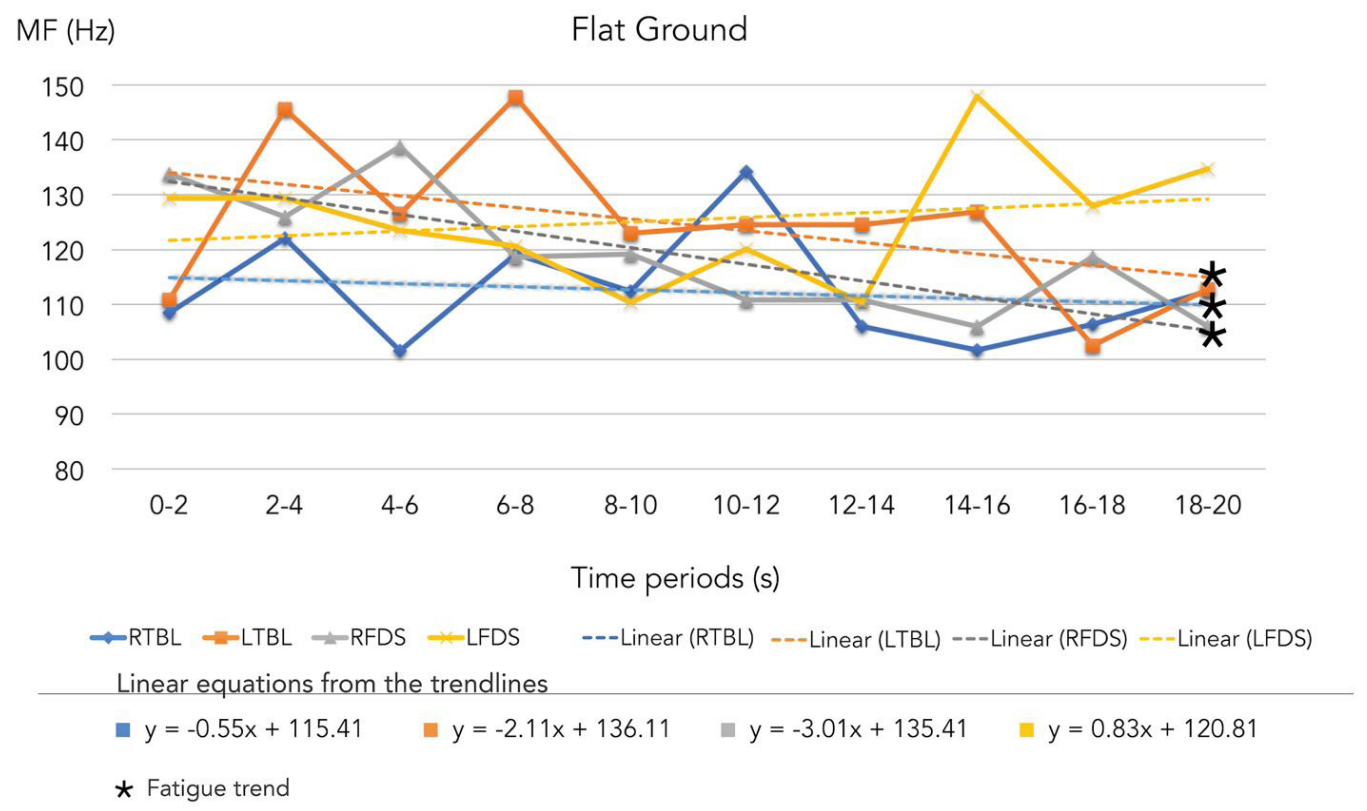

Figure 5. MF of the motor units activation in flat ground. Source: The authors (2018). 


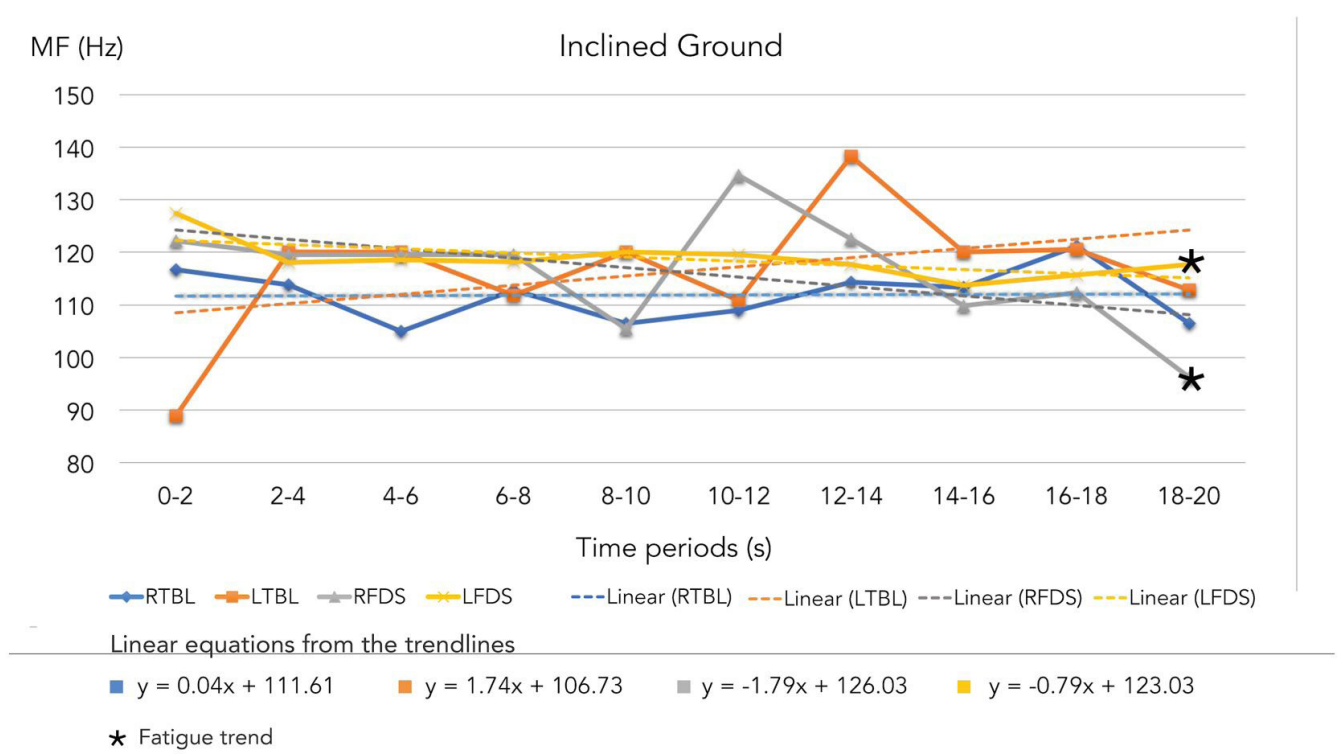

Figure 6. MF of the motor units activation in inclined ground. Source: The authors (2018).

Table 2. Risk factors and design guidelines.

\begin{tabular}{|l|l|}
\hline \multicolumn{1}{|c|}{ RISK FACTOR } & \multicolumn{1}{c|}{ GUIDELINE } \\
\hline $\begin{array}{l}\text { 1. High handgrip load, with greater myoelectric manifestation on } \\
\text { inclined ground. }\end{array}$ & $\begin{array}{l}\text { 1. Adaptation of the handle in order to reduce the predominance of } \\
\text { hand grip action, keeping the handle in neutral position and reducing } \\
\text { the need for grip during the propulsion phase on inclined ground. }\end{array}$ \\
\hline $\begin{array}{l}\text { 2. Muscle recruitment for the hand stabilization and consequent } \\
\text { mechanical efficiency reduction. }\end{array}$ & $\begin{array}{l}\text { 2. Use of rubber material in the handle to increase the friction between } \\
\text { the hand and the structure during propulsion. }\end{array}$ \\
\hline $\begin{array}{l}\text { 3. Different muscular requirements on flat and inclined ground in } \\
\text { response to acting forces. }\end{array}$ & $\begin{array}{l}\text { 3. Device for improvement of manual propulsion, adaptable to the } \\
\text { muscles requirement with the possibility of manual coupling and } \\
\text { decoupling. }\end{array}$ \\
\hline
\end{tabular}

Source: The authors (2018).

\section{Discussion}

It can be highlighted the importance of assistive technology adaptability, given that the user can spend a large part of his or her life interacting with these products. According to Chaves et al. (2004), wheelchair users consider the device as one of the factors that most limit their community participation, which demonstrates the need to think about the improvement of the wheelchair design. In the case of the individual analyzed in this study, this interaction has occurred for 33 years, therefore an experienced wheelchair user. This time of use experience, added to the sport practice, could be configured as a risk factor to the upper limbs health (DESROCHES; AISSAOUI; BOURBONNAIS, 2008). In order to evaluate the health of these segments, the manual isometric hand grip dynamometry was performed, in which the wheelchair user presented a mean strength (dominant side: $41.43 \mathrm{kgf}$, non-dominant: $46.56 \mathrm{kgf}$ ) compatible with the predicted for the male Brazilian population (dominant side: $42.8 \pm 8.9 \mathrm{kgf}$, non-dominant: $40.5 \pm 8.5 \mathrm{kgf}$ ) (CAPORRINO et al., 1998). On the other hand, it presented inferior values in the right side, when compared to the international reference for the male gender between the ages of 40 and 44 Left Side (mean: $49.8 \mathrm{kgf}$ (42.5-57.1kgf)) and Right Side [mean: $54.1 \mathrm{kgf}$ (47.1-61.2 kgf)] (BOHANNON et al., 2006).

In relation to the EMG, greater muscular activity was observed when in inclined ascending plane. Although all the muscles presented a considerable increase, there was greater fatigue of the LFDS. Richter et al. (2007), presents the importance of carrying out studies in real context due to the limitations found in laboratory studies, such as the resistance imposed by the air and the restrictions inherent to the use of treadmills.

Due to the configuration of the propulsion rim, in inclined ground it requires greater use of the musculature to stabilize the grip rather than promoting power to the wheelchair propulsion (MEDOLA et al., 2012). This is due to the reduced diameter of the rim, which does not allow contact of the palmar region and requires fine handling 
(dominated by the fingers), not providing the necessary stability to the propulsion movement (IIDA; GUIMARÃES, 2016). Also the surface low friction requires a greater force from the fingers flexor muscles to stabilize the hands in the rim and to generate sufficient friction for the wheels impulsion. Overloading of the fingers flexor muscles can lead to inflammatory lesions. According to epidemiological studies, $49 \%$ to $73 \%$ of wheelchair users have carpal tunnel syndrome (BONINGER et al., 1999).

Modifications to the wheelchair rim could, in addition to reduce the fatigue of the FDS muscle groups, increase the propulsion efficiency, since the energy could be transferred to the muscles responsible for the effective movement, potentiating the applied force (DIERUF; EWER; BONINGER, 2008), therefore, the guidelines aim to reduce the risk factors presented to the wheelchair user (Table 2).

The first defined guideline (Table 2) aims to reduce the hand grip load, adapting the handle for predominant use of the palmar region. The greater use of the palmar region increases the contact area with the handle distributing the pressure exerted, besides it offers greater stability and allows greater application of force (IIDA, GUIMAR ÃES, 2016), potentiating the propulsion movement. Medola et al. (2014), highlights the relevance of the hand grip in the wheelchair, as a contact interface that interferes with the comfort of the user and propulsion efficiency.

The second defined guideline (Table 2), aims to reduce the muscle recruitment for hand stabilization, consequently increasing the mechanical propulsion efficiency. With the use of rubber material there is a greater hand friction with the structure, increasing the handle grip. In a study by Traut (2013) with 73 wheelchair users and 24 specialists, $67 \%$ of respondents suggested the use of a material that increases the handle friction. Similarly, Van der Woude, Formanoy and De Groot (2003) in a comparative study have identified a subjective user preference for rubber-coated handles. At this point, it is important to identify a suitable friction threshold to increase the handle friction, maintaining comfort and avoiding damage to other aspects, such as wheel braking.

Considering the third presented guideline (Table 2), aims to satisfy the different muscular demands in the different contexts, flat and inclined floors. For this, a removable aid device offers greater use flexibility and can be used only when necessary. According to a study by Louis and Gorce (2010), in which electromyography was used, different patterns of muscle activity were identified in different tasks. Also Silva et al. (2017), emphasizes that the biomechanical upper limbs demand is affected by the mobility situation. The manual control of coupling and decoupling the product allows the propulsion to be carried out without damage to the wheelchair mode of use. The phases of the wheelchair manual propulsion are described in the literature (COOPER et al., 2014), the driving cycle being the main movement, which involves flexion and extension of the upper limbs joints. The cycle is divided into propulsion phase and recovery phase (Figure 7). During the propulsion phase, the hands are in contact with the rim applying force to impose acceleration to the wheels. The propulsive phase usually begins with the hands in contact with the rim slightly posterior to the user trunk, finishing with the hands in a inferior position and ahead. In the recovery phase, the arms are brought back into position to restart the cycle in the posterior region of the wheels (DAVIS; FERRARA; BYRNES, 1988). It is therefore considered that the product should follow the movement without interfering with the mobility of the wheel.

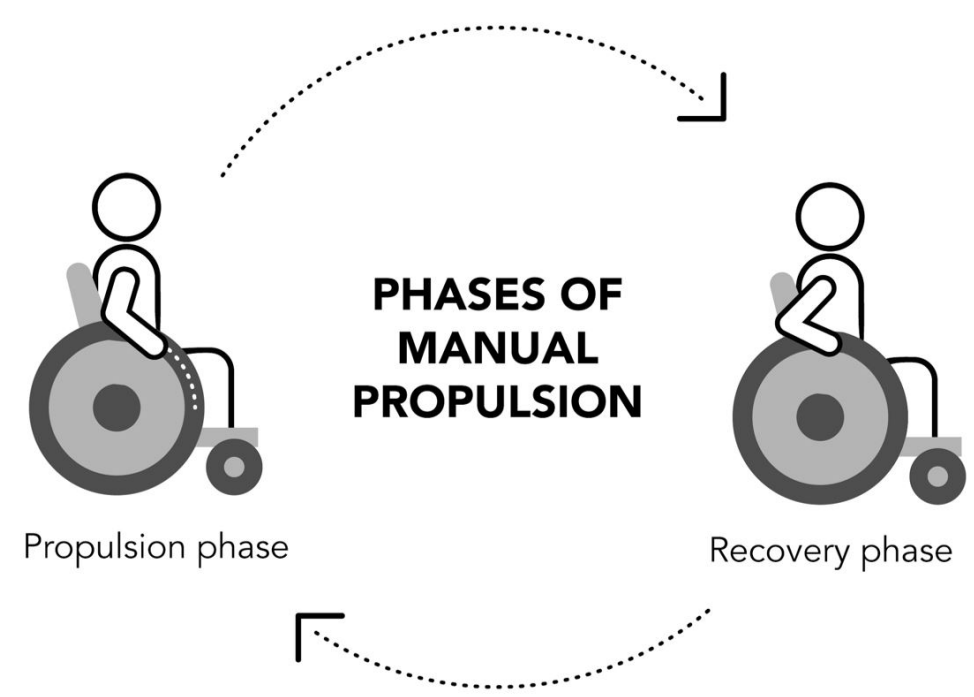

Figure 7. Phases of manual propulsion. Source: The authors based on Cooper et al. (2014). 
The defined guidelines aim to improve the wheelchair usability, being an mobility aid it should allow the safe use, avoiding, mainly, damages to the user health. These factors seek to ensure the inclusion of the PwD in order to integrate them into society and maximize their capabilities (NEWELL, 2003), so in this case the reduction of muscular effort could improve the product usability, consequently improving the conditions for independent, safe and efficient use, reducing the risk of musculoskeletal injuries associated with prolonged wheelchair use.

\section{Conclusion}

In projects for people with disabilities, it is fundamental to understand the factors involved in the users daily experience with their assistive technology devices. The use of dynamometry associated with surface electromyography allowed the quantification of isometric manual grip strength and the physical requirements of wheelchair use in flat and inclined ground contexts, generating parameters for proposing guidelines for projects that could reduce the biomechanical demands and thus better satisfy the physical needs of the user.

Regarding the Isometric Hand Grip Dinamometry, the relevance of this method in the evaluation of wheelchair users who use manual propulsion is highlighted, considering the importance of this musculoskeletal set use to the mobility and the risk of injury, inherent to the condition of propulsion.

Through the EMG, it was possible to verify greater activity of the upper limbs in the displacement in ascending inclined ground. Specifically, greater activity in the FDS muscle groups was found bilaterally, responsible for assisting the manual grip on the wheel rim. In addition to this, there was a decrease in MF values associated with an increase in the muscle use percentage, which may represent fatigue and inadequate physiological recovery of the muscle groups studied, which may lead to severe musculoskeletal disorders.

From the analysis of the physiological and biomechanical data, it was possible to identify biomechanical factors that may be related to risks to the accessed wheelchair user, thus, to suggest design guidelines for an ergonomic adaptation that can reduce physical effort, mainly on inclined ground. In this sense, reducing the need for hand grip, associated to the use of rubberized material for pressure distribution and flexibility of use, could optimize the wheelchair usability, increasing the biomechanical efficiency during manual propulsion.

Also regarding the used instruments in this research, it is important to mention that these were applied in a real wheelchair driving situation and with an experienced user, which makes this research applied and more sensitive to the need of assistive technologies users.
The aim of this study was to improve the interaction between user and assistive technology, in this case the wheelchair, considering the biomechanical aspects of manual propulsion, aiming of contributing to the inclusion and improve the PwD quality of life. Thus, ergonomics can contribute to the understanding of the assistive technology projects, considering users' perception, understanding, operation and accessibility needs.

As an opportunity for future studies it can be pointed the replication of this study with a larger number of users and the design and evaluation of a wheelchair adaptation device that meets the defined guidelines in order to reduce musculoskeletal risks for the user during manual propulsion.

\section{Acknowledgements}

The authors thank the Brazilian Coordination of Superior Level Staff Improvement (CAPES), The Brazilian National Council for Scientific and Technological Development (CNPq) the Foundation for Research and Extension (FAPEU), the Assistive Technology Research and Development Network and the Design Management Core \& Design and Usability Laboratory (NGD-LDU) from the Federal University of Santa Catarina for making this research possible.

\section{References}

BAYLEY, J. C.; COCHRAN, T. P.; SLEDGE, C. B. The weight-bearing shoulder. The impingement syndrome in paraplegics. The Journal of Bone and Joint Surgery, v. 69, n. 5, p. 676-678, 1987. http://dx.doi.org/10.2106/00004623198769050-00006.

BOHANNON, R. W. et al. Reference values for adult grip strength measured with a Jamar dynamometer: a descriptive meta-analysis. Physiotherapy, v. 92, n. 1, p. 11-15, 2006. http://dx.doi.org/10.1016/j.physio.2005.05.003.

BONINGER, M. L. et al. Wheelchair pushrim kinetics: body weight and median nerve function. Archives of Physical Medicine and Rehabilitation, v. 80, n. 8, p. 910-915, 1999. http://dx.doi.org/10.1016/S0003-9993(99)90082-5.

CAPORRINO, F. et al. Estudo populacional da força de preensão palmar com dinamômetro Jamar ${ }^{\circledR}$. Revista Brasileira de Ortopedia, v. 33, p. 150-154, 1998.

CHAVES, E. S. et al. Assessing the influence of wheelchair technology on perception of participation in spinal cord injury. Archives of Physical Medicine and Rehabilitation, v. 85 , n. 11, p. 1854-1858, 2004. http://dx.doi.org/10.1016/j. apmr.2004.03.033.

COOPER, R. A. et al. Wheelchair ergonomics. In: KUMAR, $S$. Perspectives in rehabilitation ergonomics. London: CRC Press, 2014. p. 292-323.

DAVIS, R.; FERRARA, M.; BYRNES, D. Sports performance series: the competitive wheelchair stroke. Strength and 
Conditioning Journal, v. 10, n. 3, p. 4-11, 1988. http:// dx.doi.org/10.1519/0744-0049(1988)010<0004:TCWS> 2.3. $\mathrm{CO} ; 2$.

DESROCHES, G.; AISSAOUI, R.; BOURBONNAIS, D. Relationship between resultant force at the pushrim and the net shoulder joint moments during manual wheelchair propulsion in elderly persons. Archives of Physical Medicine and Rehabilitation, v. 89, n. 6, p. 1155-1161, 2008. http://dx.doi.org/10.1016/j.apmr.2007.10.040.

DIERUF, K.; EWER, L.; BONINGER, D. The natural-fit handrim: factors related to improvement in symptoms and function in wheelchair users. The Journal of Spinal Cord Medicine, v. 31, n. 5, p. 578-585, 2008. http://dx.doi.org/1 0.1080/10790268.2008.11754605.

EVANS, D. B., HSU, J., BOERMA, T. Universal health coverage and universal access. Bulletin Of The World Health Organization, v. 91, n. 8, p. 546-546, 2013. http:// dx.doi.org/10.2471/blt.13.125450

FESS, E. E. Grip strength. In: CASANOVA, J. S. (Ed.). Clinical assessment recommendations. 2nd ed. Chicago: American Society of Hand Therapists; 1992. p. 41-45.

GELLMAN, H.; SIE, I.; WATERS, R. L. Late complications of the weight-bearing upper extremity in the paraplegic patient. Clinical Orthopaedics and Related Research, n. 233, p. 132-135, 1988.

IIDA, I.; GUIMARÃES, L. B. M. Ergonomia: projeto e produção. 3. ed. São Paulo: Blucher, 2016.

INSTITUTO BRASILEIRO DE GEOGRAFIA E ESTATÍSTICA - IBGE. Censo 2010. Rio de Janeiro, 2009. Available from: $<$ http://censo2010.ibge.gov. br/resultados $>$. Access in: 23 Jan. 2018.

LOUIS, N.; GORCE, P. Surface electromyography activity of upper limb muscle during wheelchair propulsion: Influence of wheelchair configuration. Clinical Biomechanics, v. 25, n. 9, p. 879-885, 2010. http://dx.doi.org/10.1016/j. clinbiomech.2010.07.002.

MARRAS, W. S. Industrial electromyography (EMG). International Journal of Industrial Ergonomics, v. 6, n. 1, p. 89-93, 1990. http://dx.doi.org/10.1016/01698141(90)90054-6.

MEDOLA, F. et al. A new design for an old concept of wheelchair pushrim. Disability and Rehabilitation, Assistive Technology, v. 7, n. 3, p. 234-241, 2012.

MEDOLA, F. et al. Aspects of manual wheelchair configuration affecting mobility: a review. Journal of Physical Therapy Science, v. 26, n. 2, p. 313-318, 2014. http://dx.doi. org/10.1589/jpts.26.313.

MEDOLA, F. O. et al. Dolor en individuos con lesión de la médula espinal: un estúdio descriptivo. Revista Iberoamericana de Fisioterapia y Kinesiología, v. 13, n. 2, p. 58-62, 2011. http://dx.doi.org/10.1016/j.rifk.2011.04.003.
MERLETTI, R.; DI TORINO, P. Standards for reporting EMG data. Journal of Electromyography and Kinesiology, v. 9, n. 1, p. 3-4, 1999.

MORAES, A. C. et al. Análise eletromiográfica do músculo reto femoral durante a execução de movimentos do joelho na mesa extensora. Revista Brasileira de Ciência e Movimento, v. 11, n. 2, p. 19-24, 2003.

MULROY, S. J. et al. Effects of spinal cord injury level on the activity of shoulder muscles during wheelchair propulsion: an electromyographic study. Archives of Physical Medicine and Rehabilitation, v. 85, n. 6, p. 925-934, 2004. http:// dx.doi.org/10.1016/j.apmr.2003.08.090.

NEWELL, A. Inclusive design or assistive technology. In: CLARKSON, R. et al. (Eds.). Inclusive design: design for the whole population. London: Springer, 2003. http://dx.doi. org/10.1007/978-1-4471-0001-0_11.

O'SUllivan, S. B.; SCHMiTZ, T. J.; FULK, G. D. Fisioterapia: avaliação e tratamento. São Paulo: Manole, 2017.

RICHTER, W. M. et al. Consequences of a cross slope on wheelchair handrim biomechanics. Archives of Physical Medicine and Rehabilitation, v. 88, n. 1, p. 76-80, 2007. http://dx.doi.org/10.1016/j.apmr.2006.09.015.

SILVA, S. R. M. et al. Correlação entre ativação muscular e níveis de torque propulsor em diferentes tarefas de mobilidade em cadeira de rodas. Human Factors In Design, v. 6, n. 12, p. 2-14, 2017. http://dx.doi.org/10.596 5/2316796306122017002.

SONENBLUM, S. E.; SPRIGLE, S.; LOPEZ, R. A. Manual wheelchair use: bouts of mobility in everyday life. ehabil. Rehabilitation Research and Practice, v. 753165, 2012.

TAYLOR, C.; SHECHTMAN, O. The use of the rapid exchange grip test in detecting sincerity of effort, Part I: administration of the test. Journal of Hand Therapy, v. 13, n. 3, p. 195-202, 2000. http://dx.doi.org/10.1016/S0894$1130(00) 80002-2$.

TRAUT, L. Ergonomische gestaltung der benutzerschnittstelle am antriebssystem des greifreifenrollstuhls. Berlin: Springer-Verlag, 2013.

VAN DER WOUDE, L. H. V.; FORMANOY, M.; DE GROOT, S. Hand rim configuration: effects on physical strain and technique in unimpaired subjects? Medical Engineering \& Physics, v. 25, n. 9, p. 765-774, 2003. http://dx.doi. org/10.1016/S1350-4533(03)00102-4.

WHEELCHAIR FOUNDATION. Wheelchair needs In The World. California, 2018. Available from: <https:// www.wheelchairfoundation.org/programs/from-the-heartschools-program/materials-and-supplies/analysis-ofwheelchair-need/>. Access in: 7 July 2018. 